\title{
Pedagogía Liberadora en el Pensamiento Filosófico de Bolívar
}

\author{
Cristóbal Arteta Ripoll*
}

RESUMEN

El pensamiento del Libertador ha dado para todo tipo de reflexiones y ha servido como punto de partida para ser reivindicado por unos y otros, desde la sociología, la política, la ideología y muy especialmente desde la filosofía. Son muy pocas las interpretaciones que se han hecho desde la perspectiva pedagógica. Este escrito tiene justamente la intención de mostrar los aportes de Simón Bolívar desde este enfoque teórico.

Es un recorrido histórico por la filosofía política liberadora de un hombre genial hecho historia. Para ello he utilizado, apenas, algunos documentos de una gran significación histórica, con la finalidad de mostrar la importancia de la pedagogía como formadora de líderes y forjadora de valores para la dignificación del ser humano, la optimización de los niveles y contenidos de conciencia, la perseverancia en la lucha como condición de vida y la posibilidad siempre presente de que el triunfo se transforme en derrota y la derrota en victoria.

Palabras clave

Pedagogía, Libertad, Independencia, Pensamiento filosófico, Lucha, Gloria.

ABSTRACT

The Liberator's thought has been given to all kinds of reflection and has served as a starting point to be restored by sociology, politics, ideology and especially by philosophy. There have been very few interpretations that are made from a pedagogical perspective. This paper is intended to show precisely the contributions of Simon Bolivar from this theoretical approach.

It is a historical tour trough the political liberating philosophy of a man of genius made history. For this I used some documents of great historical significance, in order to show the importance of pedagogy as a trainer of leaders and forging of values for the dignity of man, the optimization of the levels and contents of consciousness, the perseverance in the fight as a condition of life and the ever present possibility that the victory was turned into defeat and defeat into victory.

\section{Keywords}

Education, Freedom, Independence, Philosophical thought, Fight, Glory.

* Docente investigador Universidad del Atlántico y de la Universidad Libre. Director del Grupo de Investigaciones Amauta (Categoría B Colciencias) y Director de la Revista Amauta.

cristobalarteta@yahoo.es 


\section{Introducción}

El nombre del Libertador Simón Bolívar está asociado, por lo general, a la política y a la guerra. Sin embargo ya son muchos los estudios sobre su pensamiento que lo ubican como uno de los prodigios de nuestra América y del mundo. La cantidad de textos e interpretaciones sobre su obra son impresionantes y permiten una visión holística y contradictoria para afianzar la comprensión de lo que fueron los procesos de independencia en el continente americano.

Simón Bolívar (1783-1830) fue el militar y político venezolano más importante de la época pre-republicana de la Capitanía General de Venezuela, no solo por ser el gran timonel de la Gran Colombia y una de las figuras más destacadas de la emancipación americana frente al imperio español, contribuyendo de manera decisiva a la independencia de las actuales Bolivia, Colombia, Ecuador, Panamá, Perú y Venezuela, sino, además, por la profundidad de su pensamiento jusfilosófico, educativo y político.

\section{Desarrollo}

El Hombre de las Dificultades se llamó, ${ }^{1}$ tal vez, por la frecuencia de los problemas que tuvo que afrontar para llevar adelante sus planes independentistas, los cuales por su culmi- nación y éxito sirvieron para que le fuera concedido el título honorífico de Libertador por el Cabildo de Mérida en Venezuela que, tras serle ratificado en Caracas, quedó asociado definitivamente a su nombre. Refiriéndose a él dijo: el título de Libertador es superior a todos los que ha recibido el orgullo humano. ${ }^{2}$

$\mathrm{Su}$ mayor logro político fue la fundación de la Gran Colombia, nación que intentó consolidar como una gran Confederación política y militar en América, de la cual fue Presidente. Bolívar es considerado por sus acciones e ideas el Hombre de América y una destacada figura de la Historia Universal, ya que dejó un legado político en diversos países latinoamericanos, algunos de los cuales le han convertido en objeto de veneración nacionalista.

$\mathrm{Su}$ legado ideológico es inmenso y, como lo reitera el escritor cubano Pividal, en su libro: Bolivar, el precursor del pensamiento antiimperialista en América, lo que "él no hizo por hacer está todavía", porque el esfuerzo de concreción del contenido de su discurso quedó inconcluso y a merced de los intereses caudillistas y regionalistas de la época pasada y actual. Miles de interpretaciones se han hecho sobre sus ideas filosóficas, educativas y políticas, diseminadas en toda su obra teórica. Nos interesa esta

1. Así se denomina en carta dirigida al general Francisco de Paula Santander en 1825.

2. Bolívar. Carta a Páez el 6 de marzo de 1826. 
vez mostrar la pedagogía liberadora de su pensamiento, principalmente en sus más importantes documentos históricos, incluyendo su proclama en el Monte Sacro.

El ejemplo educa y de qué manera. Para el caso que nos ocupa el discípulo es obra fiel de su maestro, pero no una copia. Simón Rodríguez vivió una época de grandes transformaciones revolucionarias y, tal vez, por esa misma razón entendió dos sentencias que hizo suyas desde antes de ser pronunciadas por Nietzsche. La primera, el mejor maestro es el que pone en guardia a sus discípulos contra él, ${ }^{3} \mathrm{y}$, la segunda, el que ha nacido maestro toma las cosas en serio por sus discipulos y por sí mismo. ${ }^{4}$ Simón Rodríguez, utilizó en forma permanente la erística como el arte de la controver$s i a^{5}$ para forjar un pensamiento crítico y liberador en su discípulo. Objetivo que logró y no era para menos, pues bajo condiciones de oprobio, explotación económica e injusticia social a la pedagogía no le queda otro camino que el de ser liberadora mental para que las nuevas mentalidades sean capaces de implementar las revoluciones de su tiempo. El maestro lo comprendió y el discípulo lo asimiló con la velocidad de la luz del genio.

3. Nietzsche (2009). Aurora, reflexiones sobre los prejuicios morales. España: Edit. Debolsillo.

4. Nietzsche (1982). Más allá del bien y el mal. España: Edit. Edaf de Bolsillo, p. 92.

5. Nietzsche (1974). El libro del filósofo. Editorial Taurus, p. 132.
Y Bolívar lo reconoció con un agradecimiento que solo los genios son capaces de hacer y demostrando de paso que su maestro el gran forjador de un nuevo hombre:

Usted formó mi corazón para la libertad, para la justicia, para lo grande, para lo hermoso. Yo he seguido el sendero que usted me señaló... No puede figurarse usted cuán hondamente se han grabado en mi corazón las lecciones que usted me ha dado. ${ }^{6}$

Una introspección que nos puede ayudar a comprender la dimensión de la genialidad de Bolívar es respondiendo a la pregunta: como maestro o como discípulo ¿qué logramos o hemos logrado en nuestros primeros 20 años de vida y que valga la pena mostrar como ejemplo de un presente o pasado grande?

No tenemos por qué preocuparnos y avergonzarnos, al responder el interrogante anterior: los genios como Bolívar nacen cada centenar o centenares de años. Son los hombres historia, porque como resultado de esta son al mismo tiempo constructores de sus designios.

Tenía apenas 22 años de edad, cuando pronunció su famosa proclama:

La civilización que ha soplado de Oriente, ha mostrado aqui todas sus

6. Bolívar. Carta dirigida a su maestro Simón Rodríguez en 1797. 
fases, ha hecho ver todos sus elementos; mas en cuanto a resolver el gran problema del hombre en libertad, parece que el asunto ha sido desconocido y que el despejo de esa misteriosa incógnita no ha de verificarse sino en el nuevo mundo.

¡Juro delante de usted; juro por el Dios de mis padres; juro por ellos; juro por mi honor, y juro por mi Patria, que no daré descanso a mi brazo ni reposo a mi alma, hasta que haya roto las cadenas que los oprimen por voluntad del poder español!

¿Con que este es el pueblo de Rómulo y Numa, de Graco y los Horacios, de Augusto y Nerón, de César y de Bruto, de Tiberio y de Trojano? Aquí todas las grandezas han tenido su tipo y todas las miserias su cuna.

Este pueblo ha dado para todo, menos para la causa de la humanidad. ${ }^{7}$

La pedagogía liberadora es valiente, porque entiende que también la disciplina del conocimiento, al esforzarse por conocer, contra la inclinación de su espíritu y a menudo de su corazón, al verse obligado a negar alli donde quisiera afirmar, amar, adora, obra como artista y glorifica la crueldad. Sondear asi todas las cosas hasta en sus profundidades, excavarlas hasta sus escondrijos, es ya una manera de

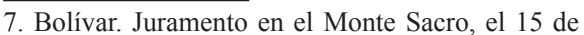
agosto de 1805, al lado de su maestro Simón Rodríguez. violentarse, de hacer sufrir intencionalmente a la voluntad fundamental del espíritu que tiende siempre hacia la apariencia y lo superficial. En toda voluntad de conocer hay, por lo menos, una gota de crueldad. ${ }^{8}$ La pedagogía liberadora comprende que solo los valientes merecen vivir la vida, aun en condiciones de miseria, dolor y sufrimiento. A los débiles no les queda otra alternativa: o aceptan el liderazgo de los valientes, o se apartan del camino o se dejan empujar hacia el abismo.

Bolívar no fue un filósofo y maestro de profesión. Fue un filósofo de la política y la guerra y un maestro de la acción. Sus enseñanzas fueron valientes y ejemplarizantes:

Todo español que no conspire contra la tiranía a favor de la justa causa por los medios más activos y eficaces, será tenido por enemigo y castigado como traidor a la Patria y en consecuencia, irremisiblemente pasado por las armas... Y vosotros, americanos, que el error o la perfidia os ha extraviado de la senda de la justicia, sabed que vuestros hermanos os perdonan y lamentan sinceramente vuestros descarríos... Españoles y canarios, contad con la muerte, aun siendo indiferentes, si no obráis activamente en obsequio de la libertad de América...

8. Nietzsche. Más allá del bien y el mal, op. cit., p. 156 .

9. Bolívar. Proclama del 15 de julio de 1813 en plena Campaña Admirable. 
La Campaña Admirable fue una acción militar enmarcada dentro de la Guerra de Independencia de Venezuela. Fue comandada por Simón Bolívar y consiguió la liberación del occidente de Venezuela, integrado en aquel entonces por las provincias de Mérida, Barinas, Trujillo y Caracas. Estos éxitos juntos con los obtenidos en oriente por Santiago Mariño darían origen a la conformación de la Segunda República de Venezuela.

En 1812 Bolívar escribió El MANIFIESTO DE CARTAGENA y en él esboza ideas de un gran contenido filosófico, jurídico y político. Busca la consolidación de un sistema centralista, autónomo y evitar la conformación de un gobierno federalista como el de Venezuela que fracasó por la naturaleza de la Constitución, el espíritu de misantropía y despotismo de los gobernantes y la oposición a la formación de un cuerpo militar que defendiera la República. Aquí algunas de esas ráfagas de luz para orientar a los soldados y criollos que luchan por la independencia. Bolívar entiende que cada proclama, cada frase encierra una directriz ética cargada de muchos contenidos axiológicos educativos necesarios para estimular la moral de las tropas, amilanar y acobardar a los realistas opresores:

No es siempre la mayoría física la que decide sino que es la superioridad de la fuerza moral la que se inclina hacia la balanza.
Un pueblo hundido al triple yugo de la ignorancia, de la tiranía y del vicio, no ha podido adquirir ni saber, ni poder, ni virtud.

No somos europeos, no somos indios, sino una especia media entre aborígenes y españoles.

Id veloz a vengar al muerto, a dar vida a los moribundos, soltura al oprimido y libertad a todos.

Corramos a romper las cadenas de aquellas víctimas que gimen en las mazmorras, siempre esperando su salvación de nosotros.

El soldado bisoño lo cree todo perdido, desde que es derrotado una vez porque la experiencia no le ha probado que el valor, la habilidad y la constancia corrigen la mala fortuna.

A cada conspiración sucedida, un perdón, y a cada perdón sucedía otra conspiración y se volvía a perdonar: porque los gobiernos liberales deben distinguirse por la clemencia.

Todos los hombres y todos los pueblos gozan de la prerrogativa de instituir a su antojo, el gobierno que les acomode.

El sistema federal bien que sea el más perfecto y más capaz de proporcionar la felicidad humana en sociedad es no obstante, el más opuesto a los intereses de nuestros salientes estados. 
Todavía nuestros ciudadanos no se hallan en actitud de ejercer por si mismos ampliamente sus derechos. Virtudes que no adquieren en los gobiernos absolutos, en donde se desconocen los derechos y deberes del ciudadano.

Mientras no centralicemos nuestros gobiernos americanos, los enemigos obtendrán las más complejas ventajas.

Nuestra división y no las armas españolas nos tornó a la esclavitud.

Si Caracas en lugar de una confederación lánguida e insubsistente hubiese establecido un gobierno sencillo lo cual requería su situación política y militar, tú existieras joh Venezuela! Y gozarías hoy de tu libertad.

Estos ejemplos de errores e infortunios, no serán eternamente inútiles para los pueblos de América meridional, que aspiran a la libertad e independencia.

Toda guerra defensiva es perjudicial y ruinosa para el que la sostiene. ${ }^{10}$

Continuando con la batalla de ideas, al mismo tiempo que comandaba las tropas contra las fuerzas realistas colonialistas, escribe en el año de 1814 otro de sus históricos documentos, tan memorable como el de Angostura: El MANIFIESTO DE CARÚPANO. El

10. Bolívar. Manifiesto de Cartagena, escrito el 15 de diciembre de 1812 . contenido de sus frases deja entrever la gran visión del Libertador, la constancia en pos del triunfo y su fe en la victoria:

El cielo para nuestra humillación y nuestra gloria ha permitido que nuestros vencedores sean nuestros hermanos y que nuestros hermanos únicamente triunfen de nosotros.

No es justo destruir los hombres que no quieren ser libres, ni es libertad la que se goza bajo el imperio de las armas contra la opinión de seres fanáticos cuya depravación de espiritu les hace amar las cadenas como los vinculos sociales.

No, no son los hombres vulgares los que pueden calcular el eminente valor del reino de la libertad, para que lo prefieran a la ciega ambición y a la vil codicia.

Es una estupidez maligna atribuir a los hombres públicos las vicisitudes que el orden de las cosas produce en los Estados.

No comparéis vuestras fuerzas fisicas con las enemigas porque no es comparable el espíritu con la materia. Vosotros sois hombres, ellos son bestias, vosotros sois libres, ellos esclavos. Combatid, pues, y venceréis.

Dios concede la victoria a la constancia.

Las armas os darán la independencia, las leyes darán libertad. 
Es dificil hacer justicia a quienes nos han ofendido.

Para nosotros la Patria es América.

Ser justos en vuestro dolor, como es justa la causa que lo produce.

Es saludable, es noble y sublime, vindicar la naturaleza ultrajada por la tirania; nada es comparable a la grandeza de este acto y aun cuando la desolación y la muerte sean el premio de tan glorioso intento, no hay razón para condenarlo.

Dichosísimo aquel que corriendo por entre los escollones de la guerra, de la política y de las desgracias públicas, preserva su honor intacto.

El hombre es débil juguete de la fortuna sobre la cual debe calcular con fundamento muchas veces, sin poder contar con ella jamás. ${ }^{11}$

El 6 de septiembre de 1815 escribe, uno de los documentos más comentado entre los historiadores: La Carta de Jamaica. Este es un texto escrito por Simón Bolívar en Kingston, en respuesta a una misiva de Henry $\mathrm{Cu}-$ llen donde expone las razones que provocaron la caída de la Segunda República en el contexto de la independencia de Venezuela. Sus centelladas parecen definitivamente iluminar el camino que faltaba por recorrer:

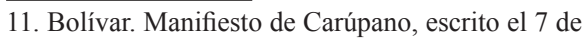
septiembre de 1814.
Los estados son esclavos por la naturaleza de su Constitución o por el abuso de ella; luego un pueblo es esclavo, cuando el gobierno por su esencia o por sus vicios, hoya y usurpa los derechos del ciudadano o súbdito.

Un estado demasiado extenso en sí mismo o por sus dependencias, al cabo viene en decadencia, y convierte su forma libre en tiránica.

La unión no nos vendrá por prodigios divinos, si no por efectos sensibles y esfuerzos bien dirigidos.

Para que un solo gobierno dé vida, anime, ponga en acción todos los resortes de la prosperidad pública, corrija, ilustre y perfeccione al nuevo mundo sería necesario que tuviese las facultades de un Dios y, cuando menos, las luces y virtudes de todos los hombres.

El interés bien entendido de una República se circunscribe en la esfera de su conservación, prosperidad y gloria.

El imperio de la costumbre produce efecto de la obediencia a las potestades establecidas.

Una parte de las estadísticas y revolución de América es conocida, me atrevo a asegurar que la mayor parte está cubierta de tinieblas...

Más grande es el odio que nos ha separado de la península que el mar que nos separa de ella. 
¿Qué demencia la de nuestro enemigo, pretender reconquistar América, sin marina, sin tesoros y casi sin soldados!

Las almas generosas se interesan en la suerte de un pueblo que se esmera por recobrar los derechos con que el creador y la naturaleza los ha dotado.

Cuando los sucesos no están asegurados, cuando el Estado es débil y las empresas son remotas, todos los hombres vacilan...

Luego que seamos fuertes, bajo los auspicios de una nación liberal que nos preste atención, se nos verá de acuerdo cultivar las virtudes y los talentos que conducen a la gloria.

Seguiremos la marcha majestuosa hacia las grandes prosperidades a que está destinada América.

Yo deseo más que otro alguno, ver formar en América la más grande nación del mundo, menos por su extensión y riquezas que por su libertad y gloria. $^{12}$

El 15 de febrero de 1819 en la provincia de Guayana, pronuncia El Discurso de Angostura con motivo de la instalación del segundo Congreso Constituyente de la República de Venezuela en San Tomé de Angostura (hoy Ciudad Bolívar). En este documento Bolívar como jefe del Estado se diri-

12. Bolívar. Carta de Jamaica, escrita el 6 de septiembre de 1815 . ge a los congresistas del país no solo para expresar su opinión sobre lo que debía ser el proyecto constitucional a sancionarse, sino también una profunda reflexión sobre la situación que vivía Venezuela a fines de 1818 . En relación al proceso de elaboración de dicho texto, el mismo se llevó a cabo fundamentalmente en su residencia de Angostura durante los últimos meses de 1818. Asimismo, no vaciló Bolívar en confiar los originales de este importante documento a Manuel Palacio Fajardo, estadista dotado de talento y erudición, para que le diera su opinión. En este sentido, Palacio Fajardo formuló algunas observaciones, que Bolívar aceptó con humildad. El 15 de febrero de 1819, día fijado para la instalación del Congreso que el propio Bolívar había convocado, una salva de cañonazos, unidos a las aclamaciones del pueblo, señaló a las 11 a.m., la llegada del Libertador, jefe supremo de la República y de la comitiva que lo acompañaría a la sede del Congreso.

En el discurso pronunciado durante casi una hora ante el Congreso de Angostura, El Libertador analizó de manera profunda la realidad de su tiempo, señalando la conveniencia de que las instituciones que surgieran en América a raíz de la Independencia, debían responder a las necesidades y posibilidades de estas sociedades, sin copiar modelos de tierras extrañas. Aunque se reconoce en este documento lo favorable del régimen federal para otras naciones; se sostiene que en el caso de Venezuela es preferible 
un Centralismo, basado en un Poder Público distribuido en las clásicas ramas: Ejecutivo, Legislativo y Judicial; resaltando la fortaleza del Ejecutivo. Sugiere también Bolívar que a estos tres poderes se agregue una cuarta instancia denominada Poder Moral, destinado a exaltar el imperio de la virtud y enseñar a los políticos a ser probos e ilustrados. Asimismo, concebía la idea de una Cámara Alta hereditaria, para mantener en ella la tradición edificante de los padres de la Patria; lo cual no encajó muy bien con la letra del Poder Moral. En una demostración de gran ilustración El Libertador hace reminiscencias de Grecia y Roma y examina las instituciones políticas de Gran Bretaña y Estados Unidos, citando para esto a filósofos y políticos de la Enciclopedia y de la Revolución Francesa, para desembocar en la necesidad de instaurar un sistema republicano-democrático, con proscripción de la nobleza, los fueros y privilegios, así como de la abolición de la esclavitud. Otro aspecto al que dedicó una importancia fundamental en el proceso de consolidación de las repúblicas latinoamericanas, fue a la educación. En este sentido, para él educar era tan importante como libertar. De lo que se desprende su memorable sentencia: Moral y luces son los polos de una República, moral y luces son nuestras primeras necesidades.

He aquí algunas de sus brillantes sentencias contenidas en tan memorable discurso:
Dichoso el ciudadano que bajo el escudo de las armas de su mando se ha convocado la soberanía nacional para que ejerza su voluntad absoluta.

Cuando cumplo con este dulce deber, me liberto de la inmensa autoridad que me agobiaba, como de la responsabilidad ilimitada que pesaba sobre mis débiles fuerzas.

En medio de este piélago de angustia no he sido más que un vil juguete del huracán revolucionario que me arrebata como una débil paja.

Fuera de este soberano cuerpo se encuentran ciudadanos que en todas épocas han mostrado valor para arrastrar peligros.

Las repetidas elecciones son esenciales en los sistemas populares, porque nada es tan peligroso como dejar permanecer largo tiempo en un mismo ciudadano el poder. El pueblo se acostumbra a obedecerle y él se acostumbrará a mandarlo.

Un justo celo es la garantía de la libertad republicana, y nuestros ciudadanos deben temer con sobrada justicia que el mismo magistrado, que los ha mandado mucho tiempo, los mande perpetuamente.

La esclavitud es la hija de las tinieblas.

Un pueblo ignorante es un instrumento ciego de su propia destrucción. 
Un pueblo pervertido si alcanza su libertad, muy pronto vuelve a perderla.

La naturaleza, la verdad, nos dota al nacer del incentivo de la libertad.

El bien, como el mal, da la muerte cuando es súbdito y excesivo.

El ejército de la justicia es el ejército de la libertad.

El individuo pugna contra la masa, la masa contra la autoridad.

¡Ángeles, no hombres, pueden únicamente existir libres, tranquilos y dichosos, ejerciendo toda la potestad soberana!

El amor a la Patria, el amor a las leyes, el amor a los magistrados son las nobles pasiones que deben absorber exclusivamente el alma de un republicano.

En una palabra, la única libertad, pues que sin ella las demás son nulas.

Un gobierno que ya no quiere dominios, sino desiertos; ciudades, sino ruinas; vasallos sino tumbas.

Nada es más peligroso como dejar permanecer largo tiempo en un mismo ciudadano el poder.

Solo la democracia es susceptible de una absoluta libertad.

Muchas naciones han sacudido la opresión; pero son rarísimas las que ha sabido gozar de un precioso momento de libertad.

Actos eminentemente liberales jamás serán demasiado admirados por la pureza que los ha dictado. ${ }^{13}$

Después de desarrollar otros tópicos relacionados con una visión sobre la grandeza y el poderío de la América libre y unida, Bolívar cierra su discurso con la siguiente exhortación al Congreso: Señor, empezad vuestras funciones: yo he terminado las mías. Tras esto hizo entrega de un proyecto de Constitución así como del Poder Moral, a fin de que fueran estudiados por los diputados, añadiendo: El Congreso de Venezuela está instalado; en él reside, desde este momento, la Soberanía Nacional. Mi espada y las de mis ínclitos compañeros de armas están siempre prontas a sostener su augusta autoridad. ;Viva el Congreso de Venezuela! ${ }^{14}$

Los últimos días de su vida fueron dolorosos, amargados, tristes y llenos de mucha desilusión, y pareciera que en Bolívar tuvo cabida la profecía nietzscheana en tanto el genio nos habita somos valientes, incluso osados, y no paramos mientes en la vida, la saludy la honra, volamos a través del día con más libertad que el águila, y nos movemos con más seguridad en la oscuridad que la lechuza. Pero de pronto nos abandona y con la misma pron-

13. Bolívar. Discurso de Angostura, pronunciado el 15 de febrero de 1819.

14. Bolívar. Discurso de Angostura, op. cit. 
titud cae sobre nosotros un profundo desaliento: no nos entendemos ya nosotros mismos, sufrimos por todas las experiencias que hemos tenido, nos sentimos como a la sombras de rocas desnudas antes de una tormenta, y al mismo tiempo como pobres almas infantiles, que tienen miedo de un ruido y una sombra. Tres cuartas partes de todo el mal que se hace en el mundo se deben al miedo: iy este es sobre todo un proceso fisiológico! ${ }^{15}$

En la Hacienda de San Pedro, en Santa Marta, a 10 de diciembre de 1830 , días antes de su muerte, pronunció su último discurso. En él dejó claro la altivez y brillantez de su pensamiento, la gallardía frente al adversario y lo que avizoraba para la posteridad:

\section{Colombianos:}

Habéis presenciado mis esfuerzos para plantear la libertad donde reinaba antes la tiranía. He trabajado con desinterés, abandonando mi fortuna y aun mi tranquilidad. Me separé del mando cuando me persuadi que desconfiabais de mi desprendimiento. Mis enemigos abusaron de vuestra credulidad y hollaron lo que me es más sagrado, mi reputación y mi amor a la libertad. He sido víctima de mis perseguidores, que me han conducido a las puertas del sepulcro. Yo los perdono.

Al desaparecer de en medio de vosotros, mi cariño me dice que debo ha-

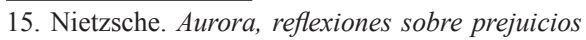
morales, op. cit., p. 339. cer la manifestación de mis últimos deseos. No aspiro a otra gloria que a la consolidación de Colombia. Todos debéis trabajar por el bien inestimable de la Unión: los pueblos obedeciendo al actual gobierno para libertarse de la anarquía; los ministros del santuario dirigiendo sus oraciones al cielo; y los militares empleando su espada en defender las garantías sociales.

¡Colombianos! Mis últimos votos son por la felicidad de la patria. Si mi muerte contribuye para que cesen los partidos y se consolide la Unión, yo bajaré tranquilo al sepulcro. ${ }^{16}$

Pero "bastó que muriera para que todos los odios se convirtieran en veneración, todas las calumnias en plegarias, todos los hechos en leyendas. Muerto ya no era un hombre sino un símbolo. La América Latina se apresuró a convertir en mármol aquella carne demasiado ardiente, y desde entonces no hubo plaza que no estuviera centrada por su imagen, civil y pensativa, o por su efigie ecuestre, alta sobre los Andes. Por fin, en el mármol se resolvía lo que en la carne pareció siempre a punto de ocurrir: que el hombre y el caballo se fundieran en una sola cosa. Aquella existencia breve como un meteoro, había iluminado el cielo de su tierra y lo había llenado no solo de sobresaltos sino de sueños prodigiosos". ${ }^{17}$

16. Bolívar. Discurso pronunciado en Santa Marta, el 10 de diciembre de 1830 .

17. Ospina, William (2010). En busca de Bolívar. Bogotá: Editorial Grupo Norma. 
Este recorrido histórico por la filosofía política liberadora de un hombre genial hecho historia, utilizando apenas algunos documentos de una gran significación histórica, nos muestra la importancia de la pedagogía como formadora de líderes y forjadora de valores para la dignificación del ser humano, la optimización de los niveles y contenidos de conciencia, la perseverancia en la lucha como condición de vida y la posibilidad siempre presente que el triunfo se transforme en derrota y la derrota en victoria.

Bolívar triunfó, porque a pesar de las lamentaciones al final de su vida lo que él no hizo se está haciendo hoy en nuestro continente y con la vigencia política de su ideario filosófico, político y pedagógico se ha iniciado de nuevo el camino de la verdadera Independencia de nuestra América.

Ha recibido todos los honores en varias partes del mundo. Pero el mejor homenaje que ha recibido se lo hacen hoy los pueblos, principalmente los pueblos latinoamericanos con los procesos de cambio, aseguramiento de la libertad y la soberanía sobre la explotación de nuestros recursos naturales para ponerlos al servicio de las gentes y no de las transnacionales del Capital. Es el más grande legado de su pedagogía liberadora.

\section{Bibliografía}

Bolívar. Carta dirigida al general Francisco de Paula Santander en 1825.
-. Carta dirigida a su maestro Simón Rodríguez en 1797.

--------. Juramento en el Monte Sacro, el 15 de agosto de 1805.

-. Proclama del 15 de julio de 1813 en plena Campaña Admirable.

Manifiesto de Cartagena, escrito el 15 de diciembre de 1812 .

Manifiesto de Carúpano, escrito el 7 de septiembre de 1814 .

Discurso de Angostura, pronunciado el 15 de febrero de 1819.

Discurso pronunciado en Santa Marta, el 10 de diciembre de 1830.

Nietzsche (2009). Aurora, reflexiones sobre los prejuicios morales. España: Edit. Debolsillo.

--------- (1982). Más allá del bien y el mal. España: Edit. Edaf de Bolsillo, p. 92.

- (1974). El libro del filósofo.

Editorial Taurus, p. 132.

Ospina, William (2010). En busca de Bolivar. Bogotá: Editorial Grupo Norma. 